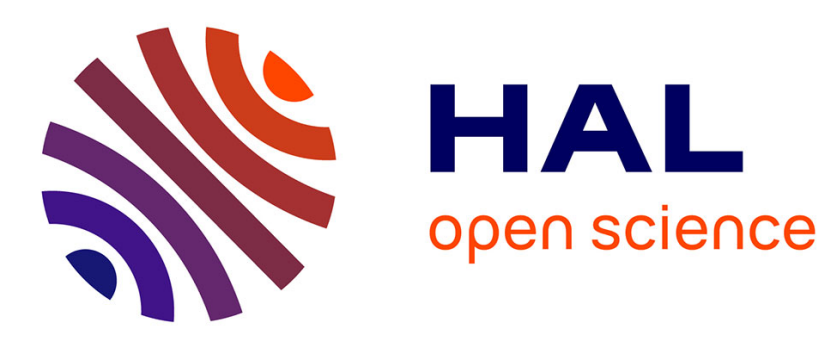

\title{
Developmental origins and homologies of the hyracoid dentition
}

Helder Gomes Rodrigues, Rodolphe Tabuce, Robert Asher, Lionel Hautier

\section{To cite this version:}

Helder Gomes Rodrigues, Rodolphe Tabuce, Robert Asher, Lionel Hautier. Developmental origins and homologies of the hyracoid dentition. Evolution and Development, 2020, e12337, 10.1111/ede.12337 . hal-02879048

\section{HAL Id: hal-02879048 \\ https://hal.sorbonne-universite.fr/hal-02879048}

Submitted on 23 Jun 2020

HAL is a multi-disciplinary open access archive for the deposit and dissemination of scientific research documents, whether they are published or not. The documents may come from teaching and research institutions in France or abroad, or from public or private research centers.
L'archive ouverte pluridisciplinaire HAL, est destinée au dépôt et à la diffusion de documents scientifiques de niveau recherche, publiés ou non, émanant des établissements d'enseignement et de recherche français ou étrangers, des laboratoires publics ou privés. 
Developmental origins and homologies of the hyracoid dentition

\section{Hyracoid dentition and mammal evolution}

Helder GOMES RODRIGUES ${ }^{1,2,3}$, Rodolphe TABUCE ${ }^{3}$, Robert J. ASHER ${ }^{4}$, Lionel HAUTIER $^{3,4}$

${ }^{1}$ Centre de Recherche en Paléontologie - Paris (CR2P), UMR CNRS 7207, CP38, Muséum national d'Histoire naturelle, Sorbonne Université, 8 rue Buffon, 75005 Paris, France

${ }^{2}$ Mécanismes adaptatifs et évolution (MECADEV), UMR 7179, CNRS, Funevol team, Muséum National d'Histoire Naturelle, 55 rue Buffon, Bat. Anatomie Comparée, CP 55, 75005 Paris Cedex 5, France

${ }^{3}$ Institut des Sciences de l'Evolution, cc64, Université de Montpellier, CNRS, IRD, EPHE, F34095 Montpellier, France

${ }^{4}$ Department of Zoology, University of Cambridge, Downing St., Cambridge CB2 3EJ, UK.

\section{Corresponding author:}

Helder Gomes Rodrigues

Email address: helder.gomes-rodrigues@mnhn.fr

Telephone: +33140793814 


\begin{abstract}
Understanding the origins of morphological specializations in mammals is a key goal in evolutionary biology. It can be accomplished by studying dental homology, which is at the core of most evolutionary and developmental studies. Here, we focused on the evolution and development of the specialized dentition of hyraxes for which dental homologies have long been debated, and could have implications on early placental evolution. Specifically, we analysed dental mineralization sequences of the three living genera of hyraxes and 17 fossil species using X-ray computed microtomography. Our results point out the labile position of vestigial upper teeth on jaw bones in extant species, associated with the frequently unusual premolar shape of deciduous canines over 50 Ma of hyracoid evolution. We proposed two evolutionary and developmental hypotheses to explain these original hyracoid dental characteristics. (1) The presence of a vestigial teeth on the maxilla in front of a complex deciduous canine could be interpreted as extra-teeth reminiscent of early placental evolution or sirenians, an order phylogenetically close to hyracoids and showing five premolars. (2) These vestigial teeth could also correspond to third incisors with a position unusually shifted on the maxilla, which could be explained by the dual developmental origin of these most posterior incisors and their degenerated condition. This integrative study allows discussion on the current evolutionary and developmental paradigms associated with the mammalian dentition. It also highlights the importance of non-model species to understand dental homologies.
\end{abstract}

Keywords: Dental ontogeny, vestigial teeth, mineralization, hyrax, mammals 


\section{INTRODUCTION}

Mammals depart from other vertebrates in showing numerous anatomical, physiological, and behavioural innovations, which greatly contributed to their diversification (Kielan-Jaworowska et al., 2004; Kemp, 2005; Luo, 2007). Among these specializations, early mammals acquired a differentiated dentition with incisors, canines, and complex postcanine teeth, with a limited number of dental generations (i.e., diphyodonty), which allow them to diversify their feeding habits (Luo et al., 2004; Luo, 2007). Using either paleontological or developmental data, many studies have focused on the origin of this differentiated, diphyodont mammalian dentition (Novacek, 1986; Luckett, 1993a; Cifelli, 2000; Zhao et al., 2000; Butler \& Clemens, 2001; Peterkova et al., 2006; Yamanaka et al., 2010; O'Leary et al., 2013; Averianov \& Archibald, 2015; O'Meara \& Asher, 2016). However, many of the associated underlying evolutionary and developmental mechanisms of the specialization of the mammalian dentition remain poorly understood. Such gaps could be overcome by unraveling the homology of dental phenotypic similarities and dissimilarities (Hall, 2003; Wagner, 2014). In that context, the study of teeth vestiges or developmental rudiments in biological models (Peterkova et al., 2006; Prochazka et al., 2010), and especially in non-model organisms (Luckett, 1993a, 1993b; Van Nievelt \& Smith, 2005; Yamanaka et al., 2010; Hautier et al., 2016), was proven to be very helpful in deciphering dental homologies and their evolutionary implications.

Among eutherian mammals (i.e., placentals and their extinct relatives), Afrotheria includes very disparate extant groups such as elephants (Proboscidea), hyraxes (Hyracoidea), sea cows (Sirenia), sengis (Macroscelidea), aardvarks (Tubulidentata), tenrecs (Tenrecidae) and golden moles (Chrysochloridae). Afrotherians also display a wide range of dental specializations regarding the shape, number, and replacement of teeth (Domning, 1982; Shoshani, 1996; Asher \& Olbricht, 2009). For example, all extinct and living hyraxes have a 
rodent-like, ever-growing upper incisor in each upper quadrant, followed in most genera by a diastema and quadritubercular cheek teeth with complex occlusal shape (Fisher 1992; Tabuce $\&$ Schmitt, 2017). In the early 19th century, Cuvier was uncertain about the identity of the first post-incisor tooth in the extant hyrax Procavia, which he recognized either as a canine (Cuvier, 1812) or as a premolar (Cuvier, 1822). The question of dental homologies was first addressed by histological studies on Procavia (Woodward, 1892; Fleischmann, 1897; Adloff, 1903) that did not achieve conclusive results regarding the nature of the first post-incisor tooth locus. More recently, Asher et al. (2017) noted for the first time the presence of a vestigial deciduous tooth (or DX) in front of the upper deciduous canine (DC, corresponding to Cuvier's "first postincisor tooth") in some foetal specimens of Heterohyrax, but were unable to definitively establish the homology of this vestigial locus.

Placental mammals have long been recognized by the constant nature of their dental formula, which includes up to three incisors followed by one canine, up to four premolars and three molars (3I, 1C, 4P, 3M; Ziegler, 1971; Novacek, 1986). Most extinct hyracoids also show this dental formula and a complete replacement of all the antemolar dentition (e.g., Gheerbrant et al., 2007). Non-placental eutherians exhibit up to five premolar loci (Novacek, 1986; Averianov \& Archibald, 2015; Bi et al., 2018). Despite conservatism among living placentals, tooth loci evident in the development of living hyracoids challenge our understanding of their basic dental formula. This suggests that hyraxes display a unique dentition compared to other placentals, in which the homology of DC and vestigial DX remain unclear.

Here, we provided new insight into the origin of the supernumerary, vestigial teeth of hyraxes based on new developmental data of the three extant genera: Procavia, Heterohyrax, and Dendrohyrax. Our collection of embryos, neonate and juvenile specimens enabled us to accurately compare the dental mineralization sequences among the three genera, after investigations of their dentition using high-resolution X-ray computed microtomography. The 
combined study of 17 extinct hyracoid species also enabled us to describe the evolution of their upper juvenile dentition over the course of $50 \mathrm{Ma}$, in order to discuss hypotheses of homology with their afrotherian sister-clades and early eutherian mammals.

\section{MATERIAL AND METHODS}

The juvenile dentition of four extant hyrax species (Procavia capensis, Heterohyrax brucei, Dendrohyrax arboreus, and D. dorsalis) was analysed on 64 original specimens (Figures 1, 2, and 3; Tables S1, S2). Dental ontogenetic series including embryos and neonate specimens of extant hyraxes were investigated using X-ray computed microtomography (EasyTom 150kV, RX solutions, University of Montpellier, France; VISCOM SARL, Saint Ouen l'Aumône, France; Helmholtz Zentrum, Berlin, Germany; the engineering department of the University of Cambridge, UK; facilities from Natural History Museum, London, UK), with different voxel sizes (Table S3). This dataset includes 31 specimens of Procavia, 13 specimens of Heterohyrax, and 9 specimens of Dendrohyrax (Table S1, Figures S1, S2, S3). 3D virtual reconstructions of the dentitions were undertaken with Avizo version 9.5 (https://www.fei.com/software/amiraavizo/) in order to characterize the dental mineralization sequence (Table 1). Collections of non-model organisms such as afrotherians often include specimens collected decades ago and the specimens studied here lack data on individual age. Except for a few putative stillborns, most of these specimens can be confidently referred to as foetuses. We also examined 58 juveniles (original, cast, or CT scan) of 17 extinct hyracoid species, with a focus on the upper deciduous dentition (Figure 4, Table S2). Two adult specimens of an early diverging hyracoid, Helioseus insolitus (Eocene, Algeria, Tabuce et al., 2011), were also imaged using X-ray computed microtomography renderings (Figure 5, Table S3).

Extant and extinct specimens are housed in the following institutions: Museum National d'Histoire Naturelle (MNHN, Paris, France), University of Montpellier (UM, Montpellier, France), Museum d'Histoire Naturelle de Toulouse (MHNT, Toulouse, France), Royal 
Museum for Central Africa (RMCA, Tervuren, Belgium), Natural History Museum, (NHM, London, UK), Museum für Naturkunde (ZMB, Berlin, Germany), Staatliches Museum für Natürkunde (SMNS, Stuttgart, Germany), Smithonian Museum (USNM, Washington, USA), American Museum of Natural History (AMNH, New York, USA), Carnegie Museum (CMNH, Pittsburgh, USA), Duke Primate Center (DPC, Durham, USA), Yale Peabody Museum (YPM, New Haven, USA), Office National des Mines (ONM, Tunis, Tunisia), General Directorate of Mineral research and exploration (MTA, Ankara, Turkey), Ditsong National Museum of Natural History (DNMNH, Pretoria, South Africa), South African Museum (SAM, Cape Town, South Africa).

Ix, C, Px and Mx refer to the xth upper incisors, canine, premolars and molars; ix, c, px and $\mathrm{mx}$ refer to the xth lower incisors, canine, premolars and molars, with a D for deciduous teeth. Teeth located on the premaxilla are counted as incisors in mammals, whereas upper canines, premolars, and molars are located only on the maxilla.

\section{RESULTS}

\subsection{Sequence of dental mineralization of extant hyraxes}

The sequence of prenatal dental eruption in Procavia is well resolved with 31 specimens and contrasts with the low resolution obtained for Heterohyrax and Dendrohyrax (13 and 9 specimens, respectively; Figure 1, Figures S1, S2, S3, Table S1). Despite these sample size differences, we noticed some similarities in their prenatal dental development, especially in early stages. All three genera show a similar pattern of mineralization of the DP2-DP3/dp2dp3), which mineralize first, followed by mineralization of DP4/dp4 and DP1/dp1, and then the DC/dc followed by M1/m1 (Table 1). However, Dendrohyrax slightly differs from Procavia in having a dc mineralizing earlier, when only dp2 and dp3 are present (Heterohyrax is not considered here because the corresponding ontogenetic stage is missing). 


\subsection{Report of vestigial or tiny teeth in extant hyraxes}

All extant hyraxes display several pairs of vestigial teeth in the maxilla, the premaxilla and the dentary during prenatal ontogeny (Figure 2, Table S1). These teeth do not develop in clearly individualized alveoli and typically lack roots, unlike other teeth. We observed vestigial teeth corresponding to DI2, which are present on both sides in 19 specimens and only on one side in three specimens (as summarized in Table S1). A vestigial dc or di3 is present but does not fully develop, in contrast to di2 (Figure 2). Vestiges of DI3 are observed only in a few specimens of Procavia and Dendrohyrax (Figure 2). These vestiges are observed bilaterally in four specimens and unilaterally in four specimens. The study of a single litter of stillborn Procavia also revealed that littermates either show missing DI2 and DI3 (CM51880), or tiny to small DI2 and DI3 on one side only (CM51882, CM51883), or tiny DI2 and DI3 on both sides, with the DI3 located at the premaxilla/maxilla suture associated with a DC merged with DP1 (CM51881; Figure 3). We furthermore observed an additional, maxillary vestigial tooth (DX), located posterior to the premaxilla/maxilla suture and anterior to the $\mathrm{DC}$, in a few specimens of Heterohyrax and Dendrohyrax (Figure 2). The DX locus is present bilaterally in four and unilaterally in one specimen, but it was not found in any of the Procavia specimens.

\subsection{Variation of the DC morphology during the evolution of hyracoids}

These dental variations occur in conjunction with a highly variable morphology of the deciduous canine and the frequent presence of a large diastema in both extant and extinct hyracoids. In all living hyrax species, the DC morphology varies from a simple (unicuspid) onerooted tooth to a two-rooted premolariform tooth with four cusps (Figure 4a-c), which is never replaced. Among extinct hyracoids, Procavia transvaalensis (Plio-Pleistocene, South Africa; see Churcher, 1956) also exhibits a one- to two-rooted upper DC with variable degrees of 
premolarisation. The pliohyracid Parapliohyrax mirabilis (Miocene, Morocco; see Ginsburg, 1977) also has a variable DC (with three $[\mathrm{N}=1]$ or four $[\mathrm{N}=4]$ main cusps) and dc (with two $[\mathrm{N}=1]$, three $[\mathrm{N}=1]$, or four [N=1] roots; Figure $4 \mathrm{~d})$. A premolarifom DC is also documented in the latest Eocene ( 34 Ma) species Saghatherium bowni (Asher et al., 2017), in the earliest Oligocene species ( 34-31.5 Ma); Saghatherium antiquum (Gheerbrant et al. 2007), and possibly in Microhyrax lavocati, one of the early diverging hyracoids, known from the late Early or early Middle Eocene ( 49-46 Ma; Figure 4f; Tabuce et al. 2007).

\section{DISCUSSION}

\subsection{Dental similarities and vestigial teeth in extant hyraxes}

Numerous similarities are observed during the prenatal mineralization of teeth in the three living genera of hyraxes. Among them, the similar pattern of DP2-DP3 mineralizing first in living hyraxes contrasts with the pattern observed in many mammals, in which the DP3-DP4 usually mineralize first (Luckett \& Maier, 1982; Stembírek et al., 2010). This unusual mineralization order might partly explain previously misidentified dental loci and resulting homologies in Procavia (see discussion in Luckett, 1993b and Asher et al., 2017). The mineralizing pattern observed in extant hyraxes (DP3 followed by DP2) is also corroborated by the wear pattern observed in most extinct hyracoids (e.g., Megalohyrax, Pachyhyrax, Saghatherium, Titanohyrax). However, we acknowledge that the timing of dental development, mineralization, eruption and wear are not strictly similar or always correlated in mammals, and can vary from one dental locus to another (e.g., Van Nievelt \& Smith, 2005).

Similarly, vestigial incisors are observed during ontogeny in all extant genera of hyraxes, which confirms previous accounts of the presence of these vestiges in both Procavia and Heterohyrax (Woodward, 1892; Fleischmann, 1897; Adloff, 1903; Luckett, 1993b). Moreover, a DX was also reported in the maxilla of Dendrohyrax, in addition to the known 
occurrence in Heterohyrax (Asher et al., 2017). In most cases, these extra teeth are present on both right and left sides (e.g., DI2, DI3, DX), which is only occasionally the case with dental anomalies, even if some of them are variably present in extant genera (e.g., absence of DX in Procavia). Since vestigial teeth were observed in a large number of specimens, their mineralization and resorption should be considered as an integral part of prenatal dental development in hyraxes and not as individual variation that occurs exceptionally within a population. Such dental loci that occur transiently during development and occasionally persist into maturity, correspond to the definition of vestigial structures (Hall, 2003).

\subsection{Canine complexity in extinct and living hyracoids and the DX locus}

The DC of hyracoids stands out for its repeated occurrence of premolar shape during the course of hyracoid evolution, and for its variable root and cusp pattern. The premolarifom design of canines is not rare in placentals, and was reported in extinct taxa, such as sloths and artiodactyls, and in extant treeshrews (Luckett, 1993b; Lihoreau \& Ducrocq, 2007; Hautier et al, 2016). In most of these cases, the canine is less complex and less variable than what we observed in hyracoids. Such large morphological variation on a single tooth locus is thus unusual in mammals. In extant hyracoids, a large diastema is generally present in front of the DC. This diastema might favour variation in dental complexity, as observed in muroid rodents for first molars (e.g., Peterkova et al., 2006). However, this assumption is not suitable here since early hyracoids did not display any diastema and had a complex DC (or C).

In a few specimens of extant Heterohyrax and Dendrohyrax (Figure 2), a vestigial tooth (DX) was observed in front of the variable DC. The DX locus is rooted in the maxilla, behind two deciduous premaxillary teeth, and thus potentially represents a ninth maxillary locus, one more than the three molars, four premolars, and one canine typically present in placental mammals. The DX locus is however absent in Procavia, which also concurs with previous 
histological results (Luckett, 1993b). Such absence is not surprising, since Procavia displays a more derived dentition (e.g., late mineralization of dc compared to Dendrohyrax and higher dental crowns; see Tabuce et al., 2017) associated with its later appearance in the fossil record than Heterohyrax and Dendrohyrax (e.g., Rasmussen et al., 1996; Pickford, 2005). This missing DX in Procavia can also be explained by a reduction of the diastema, a structure often considered as a toothless gap in mammals (e.g., Peterkova et al., 2006; Prochazka et al., 2009). Moyano et al. (2019) reported the negative allometry of the diastema during skull growth in Procavia, contrasting with the positive allometry of their cheek tooth row, conversely to Dendrohyrax. This relative reduction of the diastema in Procavia might thus be tightly associated with developmental mechanisms inhibiting the DX.

Such an abnormal number of maxillary teeth together with a diastema and premolariform canines underscore the difficulty of recognizing certain positional homologies in Hyracoidea (see Asher et al., 2017). Thus, two main, but non-mutually exclusive hypotheses emerge, based on the presence of DX combined with a complex DC: (1) the presence of a fifth premolar and (2) the development of a vestigial DI3 in the maxilla.

\subsection{Presence of a fifth premolar reminiscent of an early eutherian evolution?}

The combination of a supernumerary tooth (DX) and of a premolariform DC, both rooted in the maxilla, could indicate that the dental formula of stem hyracoids included five premolars, with the DX corresponding to the original canine locus, and the "DC" locus actually corresponding to the first premolar (i.e., DP1). Usually, the DC is one of the first teeth to develop in mammals (Luckett, 1993a), but we showed that DC mineralized late in extant hyraxes. The timing of DC mineralization in hyraxes resembles that of the DP1 of other mammals, which concurs with our assumption concerning the homology of both the DX and "DC" loci. This assumption also implies that the original canine locus would have been rapidly 
lost during the evolutionary history of hyracoids, and that only vestiges would remain in some extant species. This case of a retention of dental vestiges over tens of millions years was also reported in other mammals, such as mice and sloths (Peterkova et al., 2006; Hautier et al., 2015). Such a hypothesis is in line with the extreme molarization of the deciduous and adult canines of pliohyracids (Figure 4d) and the premolariform canines observed in all Paleogene hyracoids, including the earliest and basalmost hyracoids (Seggeurius, Helioseus, and Microhyrax) (Figure 4e-f; Tabuce et al., 2011; Benoit et al., 2016).

Another line of evidence consistent with this first hypothesis is that one adult specimen of Helioseus insolitus (UM HGL51-73), among eight specimens corresponding to maxillae with upper canines, shows a dental formula of 3I, 1C, 4P, 3M plus an additional maxillary tooth in front of right and left canines (Figure 5). At first glance, this additional tooth could correspond to an anomalous, persistent DC in front of the adult canine. However, its morphology is too simple to support such a hypothesis, as mammals generally have a more complex DC than C. Consequently, this tooth more likely represents a persistent canine, and the next tooth distally represents a P1 (and not a C), a case reminiscent of the five premolar loci seen among many non-placental eutherians (Averianov \& Archibald, 2015; Bi et al., 2017).

A fifth premolar locus is also present among other afrotherians, namely stem sirenians (Domning, 1982). Sirenians, hyracoids, and proboscideans are strongly supported in the clade Paenungulata (Tabuce et al., 2008; Esselstyn et al., 2017). If the dental formula with five premolars was widespread in early eutherian mammals (Novacek, 1986; Hu et al., 2010; Luo et al., 2011), the original third premolar locus was lost during their evolutionary history, and thus in placentals (O'Leary et al., 2013; Averianov \& Archibald, 2015). The retention of that "P3" locus in some afrotherians, meaning that the tooth is still present or subsequently rescued, would constitute the basic premise to explain the presence of five premolars in their dental formula. However, another scenario could also prevail in the case of hyracoids, as previously 
proposed for sirenians (Domning, 1982; Domning et al., 1986). The additional premolar locus may be a new one, independent of the putative "P3" locus lost in placental mammals. Such innovation was reported in Libycosaurus, a Pliocene hippopotamoid belonging to another clade of placentals, the Cetartiodactyla (Lihoreau et al., 2006). In contrast to early eutherians, its supernumerary tooth was assumed to be anterior to all other premolars and posterior to the canine, a configuration that could also prevail in stem hyracoids. The hypothesis of five premolars would benefit from additional data on early stages of dental development (i.e. before mineralization) in Dendrohyrax, Heterohyrax, and extant sirenians, as previously performed in Procavia (Luckett 1993b). Such investigations would enable to accurately compare developmental dental sequence in order to discuss dental homologies between these groups.

\subsection{Dual developmental origin of distal incisors might explain a maxillary incisor}

The second main hypothesis does not take into account the premolarifom DC and the single odd specimen of Helioseus displaying five premolars. It rather relies on the fact that the vestige of DI3 is consistently missing in both Heterohyrax and Dendrohyrax when the DX is present, while the opposite is true in Procavia and Dendrohyrax. Moreover, some of these vestigial teeth are often located at premaxilla/maxilla junction. Such observations could argue in favour of a more developmental explanation. The DI3 and DX either mineralize at different times and several early developmental events are missed, or they simply correspond to the same dental locus. This latter explanation implies that the DI3 has a variable position within the jaw, and can occasionally be located on the maxilla, and not on the premaxilla as typically observed in mammals. Following this latter hypothesis, the unusual presence of an incisor on the maxilla could be explained by the dual developmental origin of the most posterior incisors, as the upper jaw is formed by both the medial nasal prominence and the maxillary prominence during the ontogeny of mammals (Putnová et al., 2011; Yamanaka et al., 2015; Figure 6a, b). In many 
mammals, only the DI1 originates from the medial nasal prominence, while the DI2 originates from both the medial nasal prominence and the maxillary prominence, or only from the maxillary prominence, as with the DI3 when present (Peterkova et al., 1993; Putnová et al., 2011; Yamanaka et al., 2015; Hovorakova et al., 2018). Then, during bone formation, the premaxillae shift and grow distally to encapsulate the DI2 and DI3. This explains why "lateral" incisors with dual developmental origin (DI2 or DI3) can be absent, split or more distally located close to the canine in mammals with developmental premaxillary disruptions involved in the formation of a cleft palate (Wei et al., 2000; Putnová et al., 2011; Garib et al., 2015).

In extant hyraxes, the prolonged growth and larger size of the DI1 could trigger a developmental disruption or inhibition of DI2 and DI3 developing later, and lead to a more distal location of these teeth on the premaxilla. This configuration is suggested by the presence of a large DI1 and small DI2 and DI3 in both living and fossil hyracoids (Gheerbrant et al. 2007; Asher et al. 2017), meaning that the enlargement of DI1 could have occurred at the expense of DI2 and DI3. Such variation in DI2 and DI3 was observed in a single litter of stillborn Procavia in which one specimen shows a small DI3 located at the premaxilla/maxilla suture (CM51881; Figure 3B; Wible and West, 2017). A similar, distal position of the DI3 (or I3), located at level of the premaxilla/maxilla suture, was also observed in extinct hyracoids, such as Parapliohyrax (Figure 4) and Helioseus (Figure 5). This pattern has been reported in primates with a cleft palate (Wei et al., 2000; Garib et al., 2015), but developmental disruption of premaxilla has not previously been reported in extant hyraxes. Mammalian incisors generally do not erupt into the maxilla, although very high-crowned incisors do invade the maxilla in some species (e.g., rodents). Maxillary incisors have also been reported in some non-placental eutherians (e.g., Zalambdalestes, Acristatherium, see Wible et al., 2004; Hu et al., 2010). Given that distal incisors have a maxillary developmental origin in placentals, thus, an occasional location of an incisor locus on the maxilla cannot be excluded. The occurrence of incisors on 
the maxilla might be explained by the relaxed structural constraint on vestigial incisors coupled with the development of a diastema mesial to the DC in Dendrohyrax and Heterohyrax, which leaves more room for their development. Further developmental data on soft tissues would help to support this assumption by comparing initial development of the bone structures and dental domains.

\section{CONCLUSIONS}

The present investigation on the highly specialized and unique dentition of living and extinct hyracoids raises new questions regarding the origin and setting of the characteristics of the mammalian dentition. We suggest that the vestigial teeth of hyraxes might represent either extra-teeth reminiscent of those present in Mesozoic eutherian mammals, or vestigial incisors with a position shifted on the maxilla. Even if we cannot go further in our interpretations based on current data, these findings are highly promising for a better understanding of the evolution of both early placental and afrotherian mammals, and can have important phylogenetic insights. New developmental data on extant and extinct species are needed from other non-model species, especially hyracoid sister taxa (i.e., elephants, sea cows), to disentangle these homology issues.

\section{REFERENCES}

Adloff, P. (1903). Zur Kenntnis des Zahnsystems von Hyrax. Zeitschrift für Morphologie und Anthropologie, 5, 181-200.

Asher, R. J., Gunnel, G. F., Seiffert, E. R., Pattinson, D., Tabuce, R., Hautier, L., \& Sallam, H. M. (2017). Dental eruption and growth in Hyracoidea (Mammalia, Afrotheria). Journal of Vertebrate Paleontology, 37, e1317638.

Asher, R. J., \& Olbricht, G. (2009). Dental Ontogeny in Macroscelides proboscideus 
(Afrotheria) and Erinaceus europaeus (Lipotyphla). Journal of Mammalian Evolution, $16,99-115$.

Averianov, A. O., \& Archibald, J. D. (2015). Evolutionary transition of dental formula in Late Cretaceous eutherian mammals. The Science of Nature, 102, 56.

Barrow, E. C., Seiffert, E. R., \& Simons, E. L. (2010). A primitive hyracoid (Mammalia, Paenungulata) from the early Priabonian (late Eocene) of Egypt. Journal of Systematic Palaeontology, 8, 213-244.

Benoit, J., Crochet, J.-Y., Mahboubi, M., Jaeger, J.-J., Bensalah, M., Adaci, M., \& Tabuce, R. (2016). New material of Seggeurius amourensis (Paenungulata, Hyracoidea), including a partial skull with intact basicranium. Journal of Vertebrate Paleontology, 36, e1034358.

Bi, S., Zheng, X., Wang, X., Cignetti, N. E., Yang, S., \& Wible, J. R. (2018). An Early Cretaceous eutherian and the placental-marsupial dichotomy. Nature, 558, 390-395.

Butler, P. M., \& Clemens, W. A. (2001). Dental morphology of the jurassic holotherian mammal Amphitherium, with a discussion of the evolution of mammalian post-canine dental formulae. Palaeontology, 40, 1-20.

Churcher, C. S. (1956). The fossil Hyracoidea of the Transvaal and Taungs deposits. Annals of the Transvaal Museum, 22, 477-501.

Cifelli, R. L. (2000). Counting premolars in early eutherian mammals. Acta Palaeontologica Polonica, 45, 195-198.

Cooper, L. N., Seiffert, E. R., Clementz, M., Madar, S. I., Bajpai, S., Hussain, S. T., \& Thewissen, J. G. M. (2014). Anthracobunids from the Middle Eocene of India and Pakistan are stem perissodactyls. Plos One, 9, e109232.

Cuvier, G. (1812). Recherches sur les ossemens fossiles de quadrupèdes. Tome second. Paris: Déterville. 
Cuvier, G. (1822). Recherches sur les ossemens fossiles, où l'on rétablit les caractères de plusieurs animaux dont les révolutions du globe ont détruit les espèces. (Dufour, G. D'Ocagne, E. ed. Vol. Tome Troisième). Paris.

Domning, D. P. (1982). Evolution of manatees; a speculative history. Journal of Paleontology, $56,599-619$.

Domning, D. P., Ray, C. E., \& McKenna, M. C. (1986). Two new Oligocene desmostylians and a discussion of tethytherian systematics. Smithsonian Contributions to Paleobiology, $59,1-56$.

Esselstyn, J. A., Oliveros, C. H., Swanson, M. T., \& Faircloth, B. C. (2017). Investigating Difficult Nodes in the Placental Mammal Tree with Expanded Taxon Sampling and Thousands of Ultraconserved Elements. Genome Biology and Evolution, 9, 2308-2321. Fischer, M.S. (1992) Hyracoidea. Handbuch der Zoologie. Band VIII Mammalia: Berlin and New York, Walter de Gruyter, 176 p.

Fleischmann, A. (1897). Mitteilungen über die Zahnentwicklung von Hyrax. Abhandlungen der Naturhistorischen Gesellschaft Nurnberg, 10, 47-54.

Garib, D. G., Rosar, J. P., Sathler, R., \& Ozawa, T. O. (2015). Dual embryonic origin of maxillary lateral incisors: clinical implications in patients with cleft lip and palate. Dental Press Journal of Orthodontics, 20, 118-125.

Gheerbrant, E., Peigné, S., Thomas, H. (2007). Première description du squelette d'un hyracoïde paléogène: Saghatherium antiquuum de l'Oligocène inférieur de Jebel al Hasawnah, Libye. Palaeontographica Abteilung A., 279, 93-145.

Ginsburg, L. (1977). L'hyracoïde (mammifère subongulé) du Miocène de Beni Mellal (Maroc). Géologie Méditerranéenne, 4, 241-253.

Hall, B. K. (2003). Descent with modification: the unity underlying homology and homoplasy as seen through an analysis of development and evolution. Biological Reviews, 78, 409- 
433.

Hautier, L., Gomes Rodrigues, H., Billet, G., \& Asher, R. J. (2016). The hidden teeth of sloths: evolutionary vestiges and the development of a simplified dentition. Scientific Reports, 6, 27763.

Hovorakova, M., Lesot, H., Peterka, M., \& Peterkova, R. (2018). Early development of the human dentition revisited. Journal of anatomy, 233, 135-145.

Hu, Y., Meng, J., Li, C., \& Wang, Y. (2010). New basal eutherian mammal from the Early Cretaceous Jehol biota, Liaoning, China. Proceedings of the Royal Society B: Biological Sciences, 277, 229-236.

Kemp, T. S. (2005). The origin and evolution of Mammals: Oxford university press.

Kielan-Jaworowska, Z., Cifelli, R. L., \& Luo, Z.-X. (2004). Mammals from the Age of Dinosaurs. Origins, evolution and structure. New York: Columbia university press.

Lihoreau, F., Boisserie, J.-R., Viriot, L., Coppens, Y., Likius, A., Mackaye, H. T., . . Brunet, M. (2006). Anthracothere dental anatomy reveals a late Miocene Chado-Libyan bioprovince. Proceedings of The National Academy of Science, 103, 8763-8767.

Lihoreau, F. \& Ducrocq, S. (2007) Family Anthracotheriidae. In D.R. Prothero \& S.E. Foss (Eds.), The Evolution of Artiodactyls (pp. 89-105). Baltimore: The Johns Hopkins Univ. Press.

Luckett, W. P. (1993a). An ontogenetic assessment of dental homologies in therian mammals. In F. S. Szalay, M. J. Novacek, \& M. C. McKenna (Eds.), Mammal Phylogeny-Mesozoic Differentiation, Multituberculates, Monotremes, Early Therians, and Marsupials (Vol. 2, pp. 182-204). New York: Springer-Verlag.

Luckett, W. P. (1993b). Ontogenetic Staging of the Mammalian Dentition, and Its Value for Assessment of Homology and Heterochrony. Journal of Mammalian Evolution, 1(4), 269-282. 
Luckett, W. P., \& Maier, W. (1982). Development of Deciduous and Permanent Dentition in Tarsius and Its Phylogenetic Significance. Folia Primatologica, 37, 1-36.

Luo, Z.-X. (2007). Transformation and diversification in early mammal evolution. Nature, 450, 1011-1019.

Luo, Z.-X., Kielan-Jaworowska, Z., \& Cifelli, R. L. (2004). Evolution of dental replacement in mammals. Bulletin of Carnegie Museum of Natural History, 36, 159-175.

Luo, Z.-X., Yuan, C.-X., Meng, Q.-J., \& Ji, Q. (2011). A Jurassic eutherian mammal and divergence of marsupials and placentals. Nature, 476, 442-445.

Moyano, S. R., Cassini, G. H., \& Giannini, N. P. (2019). Skull Ontogeny of the Hyraxes Procavia capensis and Dendrohyrax arboreus (Procaviidae: Hyracoidea). Journal of Mammalian Evolution, 26, 317-331.

Novacek, M. J. (1986). The primitive eutherian dental formula. Journal of Vertebrate Paleontology, 6, 191-196.

O'Leary, M. A., \& al., e. (2013). The Placental Mammal Ancestor and the Post-K-Pg Radiation of Placentals. Science, 339, 662.

O'Meara, R. N., \& Asher, R. J. (2016). The evolution of growth patterns in mammalian versus non-mammalian cynodonts. Paleobiology, 42, 439-464.

Peterkova, R., Lesot, H., \& Peterka, M. (2006). Phylogenetic Memory of Developing Mammalian Dentition. Journal of Experimental Zoology, 306B, 234-250.

Peterkova, R., Peterka, M., Vonesch, J.-L., \& Ruch, J. V. (1993). Multiple developmental origin of the upper incisor in mouse: histological and computer assisted 3-D-reconstruction studies. International Journal of Developmental Biology, 37, 581-588.

Pickford, M. 2005. Fossil hyraxes (Hyracoidea: Mammalia) from the Late Miocene and PlioPleistocene of Africa, and the phylogeny of the Procaviidae. Palaeontologia Africana, $41,141-161$. 
Prochazka, J., Pantalacci, S., Churava, S., Rothova, M., Lambert, A., Lesot, H., . . Peterkova, R. (2010). Patterning by heritage in mouse molar row development. Proceedings of The National Academy of Science, 107(35), 15497-15502.

Putnová, I., Odehnalová, S., Horák, V., Stehlík, L., Míšek, I., Lozanoff, S., \& Buchtová, M. (2011). Comparative morphology of normal and cleft minipigs demonstrates dual origin of incisors. Archives of Oral Biology, 56, 1624-1634.

Rasmussen, D. T., Pickford, M., Mein, P., Senut, B., \& Conroy, G. C. (1996). Earliest known procaviid hyracoid from the Upper Miocene of Namibia. Journal of Mammalogy, 77, $745-754$.

Shoshani, J. (1996). Skeletal and other basic anatomical features of elephants. In J. Shoshani \& P. Tassy (Eds.), The Proboscidea, evolution and palaeoecologyy of elephants and their relatives (pp. 9-20). Oxford, New York,Tokyo: Oxford science publication.

Stembírek, J., Buchtová, M., Král, T., Matalová, E., Lozanoff, S., \& Míšek, I. (2010). Early morphogenesis of heterodont dentition in minipigs. European Journal of Oral Sciences, $118,547-558$

Tabuce, R., Charruault, A.-L., Adaci, M., Bensalah, M., Ben Haj Ali, M., Essid, E. M., .. . Mahboubi, M. (2011). The early Eocene radiation of Hyracoidea (Mammalia, Afrotheria): new fieldwork evidence from North-western Africa. Paper presented at the The World At The Time of Messel: Puzzles in Palaeobiology, Palaeoenvironment and the History of Early Primates. 22nd International Senckenberg Conference Frankfurt.

Tabuce, R., Lehmann, T., \& Asher, R. J. (2008). Afrotherian mammals: a review of current data. Mammalia, 72, 2-14.

Tabuce, R., Marivaux, L., Adaci, M., Bensalah, M., Hartenberger, J.-L., Mahboubi, M., Mebrouk, F., Tafforeau, P., \& Jaeger, J.-J., 2007. Early Tertiary mammals from North 
Africa reinforce the molecular Afrotheria clade. Proceedings of the Royal Society B: Biological Science, 274, 1159-1166.

Tabuce, R \& Schmitt, S. (2017) De l'ombre aux Lumières et réciproquement : redécouverte du crâne de Procavia capensis (Pallas, 1766) (Hyracoidea, Mammalia) décrit en 1767 par Daubenton dans l'Histoire naturelle. Zoosystema, 39, 487-499.

Tabuce, R., Seiffert, E. R., Gheerbrant, E., Alloing-Séguier, L., \& Koenigswald, W. v. (2017). Tooth enamel microstructure of living and extinct hyracoids reveals unique enamel types among mammals. Journal of Mammalian Evolution, 24, 91-110.

Van Nievelt, A. F. H., \& Smith, K. K. (2005). To replace or not to replace: the significance of reduced functional tooth replacement in marsupial and placental mammals. Paleobiology, 31, 324-346.

Wagner, G. P. (2014). Homology, Genes, and Evolutionary Innovation. Princeton: Princeton University Press.

Wei, X., Senders, C., Owiti, G. O., Liu, X., Wei, Z. N., Dillard-Telm, L., . . Hendrickx, A. G. (2000). The Origin and Development of the Upper Lateral Incisor and Premaxilla in Normal and Cleft Lip/Palate Monkeys Induced With Cyclophosphamide. Cleft Palate Craniofac J., 37, 571-583.

Wible, J. R., Novacek, M. J., \& Rougier, G. W. (2004). New data on the skull and dentition in the Mongolian Late Cretaceous eutherian mammal Zalambdalestes. Bulletin of the American Museum of Natural History, 281, 1-144.

Wible, J.R., \& West, A.R. (2017). The basicranial axis in the rock hyrax, Procavia capensis (Pallas, 1766) (Mammalia, Afrotheria, Hyracoidea): novel structure of the frontal bone. Annals of Carnegie Museum, 84, 287-300.

Woodward, M. F. (1892). On the milk dentition of Procavia (Hyrax) capensis and of the rabbit (Lepus cunniculus), with remarks on the relation of the milk and permanent dentitions 
of the Mammalia. Proceedings of the Zoological Society of London, 38-49.

Yamanaka, A., Iwai, H., Uemura, M., \& Goto, T. (2015). Patterning of mammalian heterodont dentition within the upper and lower jaws. Evolution and Development, 17, 127-138.

Yamanaka, A., Yasui, K., Sonomura, T., Iwai, H., \& Uemura, M. (2010). Development of deciduous and permanent dentitions in the upper jaw of the house shrew (Suncus murinus). Archives of Oral Biology, 55, 279-287.

Zhao, Z., Weiss, K., \& Stock, D. (2000). Development and evolution of dentition patterns and their genetic basis. In M. F. Teaford, M. M. Smith, \& F. M.W.J (Eds.), Development, function, and evolution of teeth (pp. 152-172). Cambridge: Cambridge University Press.

Ziegler, A. C. (1971). A theory of the evolution of therian dental formulas and replacement patterns. The Quarterly Review of Biology, 46, 226-249.

\section{ACKNOWLEDGEMENTS}

We are grateful to the curators G. Billet, J. Lesur, M. Herbin, C. Bens, F. Renoult, C. Denys, J. Cuisin (MNHN), S. Jiquel (UM), Yves Laurent (MHNT), W. Wendelen, E. Gilissen (RMCA), P. Jenkins, L. Tomsett, R. Portela Miguez, P. Brewer (NHM), P. Giere, F. Mayer (Museum für Naturkunde), R. Ziegler (SMNS), D. Lunde (USNM), J. Galkin (AMNH), G. Gunnell and C. Riddle (DPC), D. Brinkman (YPM), Rim Temani (ONM), Stephany Potze (DNMNH), N. Bennett, H. Viljoen (University of Pretoria) who allowed access to zoological and paleontological collections. We gratefully acknowledge J. Wible for pictures of Procavia from the CM, and S. R. Moyano (Universidad Nacional de Jujuy) for pictures of Dendrohyrax from the AMNH. We also thank R. Lebrun (ISEM) for the access of scanning facilities (MRI platform member of the national infrastructure France-BioImaging supported by the French National Research Agency [ANR-10-INBS-04, «Investments for the future»], the LabEx CEMEB [ANR-10-LABX-0004] and NUMEV [ANR-10-LABX-0020]), A.-L. Charruault 
(ISEM) for preparing and scanning the specimens of Helioseus, D. Pattinson (University of Cambridge) for help during scanning, and to C. Soubiran (UM) for preliminary studies on extant hyracoids. This work has been supported by the French ANR-PALASIAFRICA Program (ANR-08-JCJC-0017, ANR-ERC), Research Council of University of Montpellier, and by “Investissements d'Avenir" grants managed by Agence Nationale de la Recherche Labex CEBA (ANR-10-LABX-25-01). L.H. was supported by a European Research Council (ERC) consolidator grant [ConvergeAnt \#683257]. We also thank three anonymous reviewers who greatly helped to improve this article.

\section{CONFLICT OF INTERESTS}

The authors declare that there are no conflict of interests.

\section{AUTHOR CONTRIBUTIONS}

R.T. and L.H. conceived and designed the study. H.G.R., R.T. and L.H. performed research and analysed the data. All authors contributed to write, review and improve the manuscript, and approved it.

TABLE 1 Dental mineralization sequence of extant genera of hyraxes

\begin{tabular}{|c|c|c|}
\hline Genus & Dentition & Mineralizing sequence \\
\hline \multirow[t]{2}{*}{ Procavia } & Upper & DI1, DP2, DP3 -> DP1, DP4 -> DI2 -> DI3 -> DC -> M1 -> M2 \\
\hline & Lower & di2, dp2, dp3 -> di1, dp4 -> dp1 $>>$ di3 or dc $\rightarrow$ m1 $\rightarrow>$ m2 \\
\hline \multirow[t]{2}{*}{ Heterohyrax } & Upper & DP3 -> DI1, DX, DP1, DP2, DP4 -> DI2 -> DC \\
\hline & Lower & dp3 -> dp2 -> di1, di2, di3 or dc, dp1, dp4 \\
\hline \multirow{2}{*}{ Dendrohyrax } & Upper & DP2, DP3 -> DI1, DP4 -> DI2, DI3 -> DC, DP1 -> DX, M1 \\
\hline & Lower & dc, dp2, dp3 -> di2 -> dp4 -> di1 -> dp1 -> m1 \\
\hline
\end{tabular}

\section{Figure captions}


FIGURE 1 CT reconstructed scans of the developing skull in extant hyraxes representing the main mineralizing stages of the dentition. Procavia: (a) MNHN 1886-320, (b) MNHN 1901685e, (c) MNHN 1961-44, (d) MNHN 1901-685c, (e) MNHN 1981-994; Heterohyrax: (f) USNM 184769, (g) USNM-1639, (h) USNM-181604, (i) USNM-1433-2, (j) USNM-1956-723; Dendrohyrax: (k) RMCA-16559, (1) RMCA-14058, (m) RMCA-20635, (n) MNHN 1883-868, (o) RMCA-19881. The premaxilla is indicated in pink in some specimens. 
Procavia
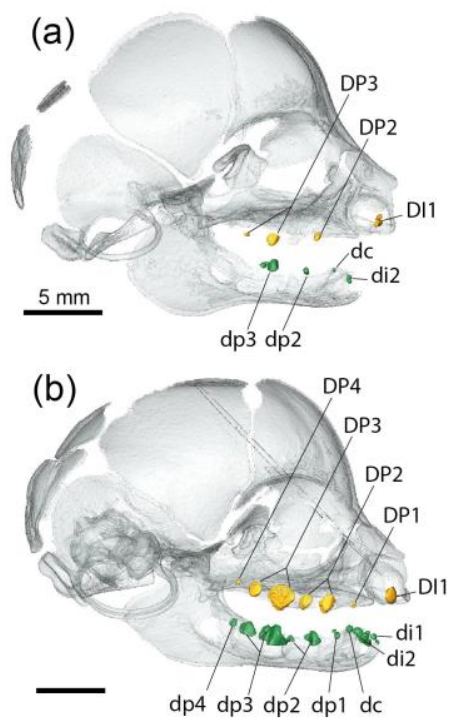

(c)

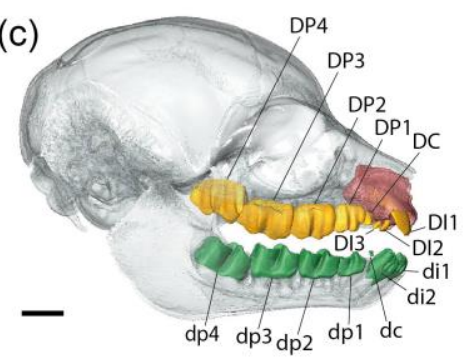

(d)

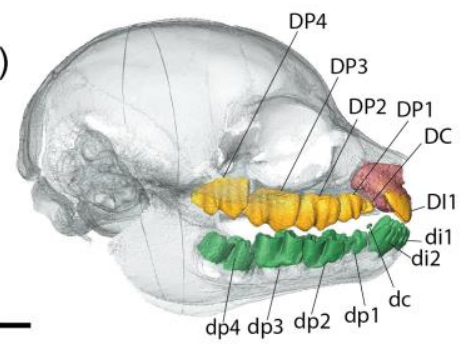

(e)

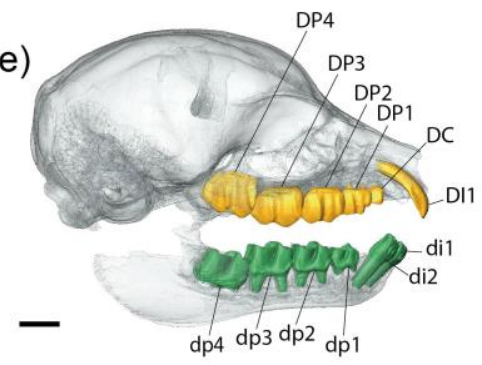

Heterohyrax
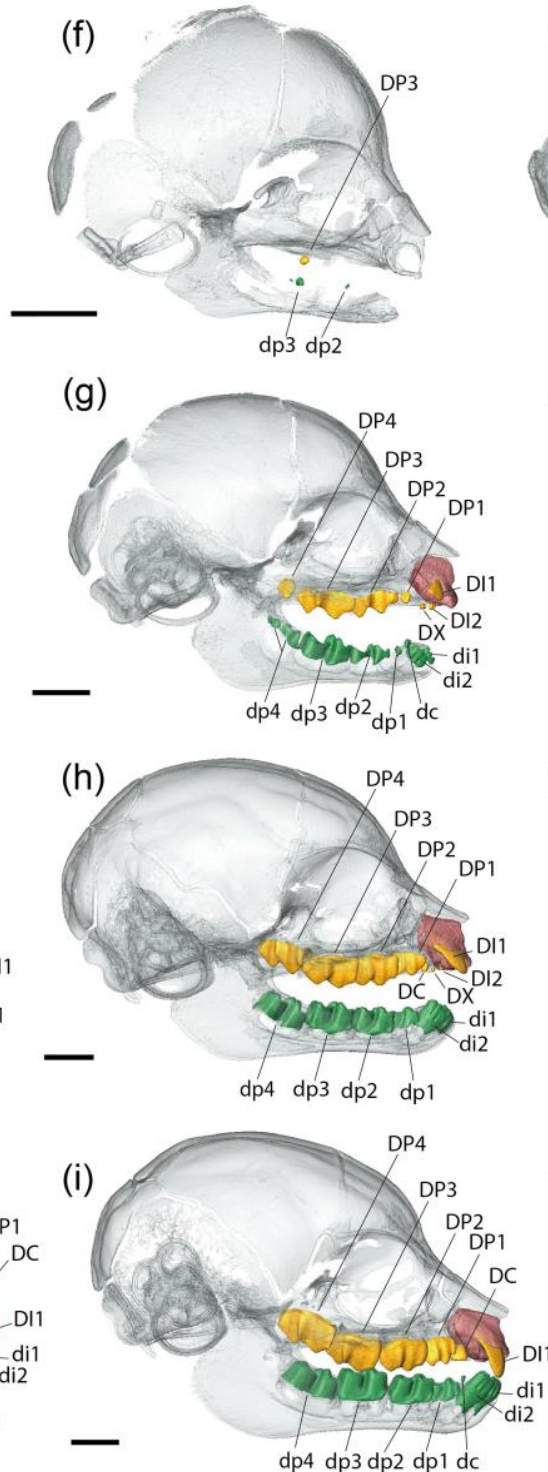

(j)

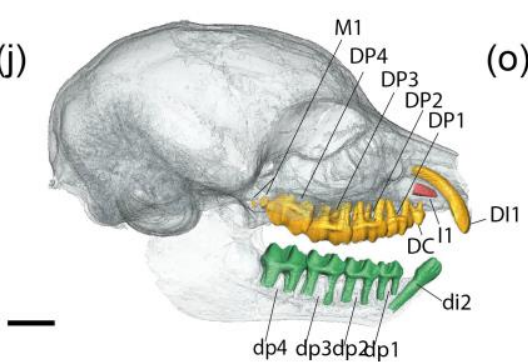

Dendrohyrax
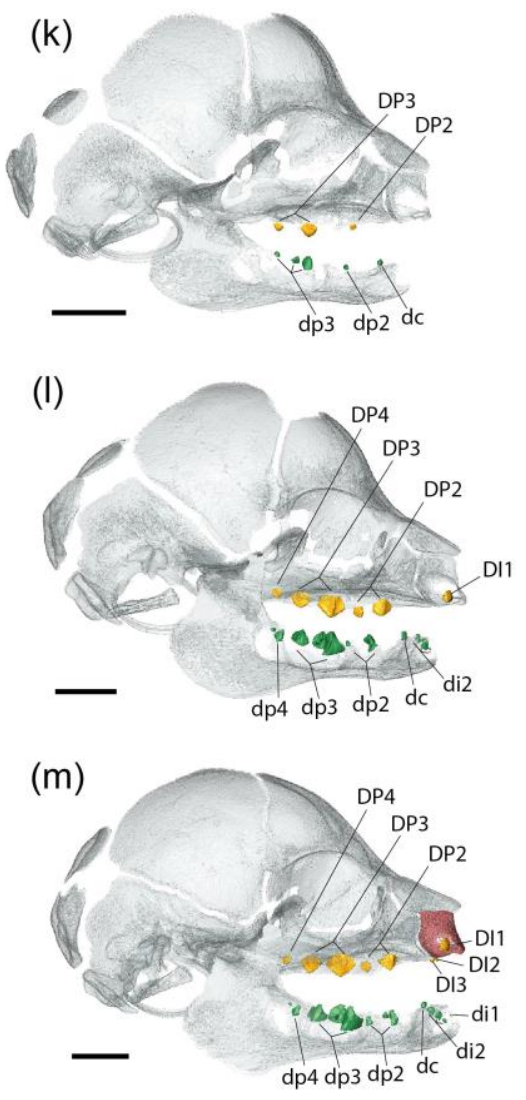

(n)

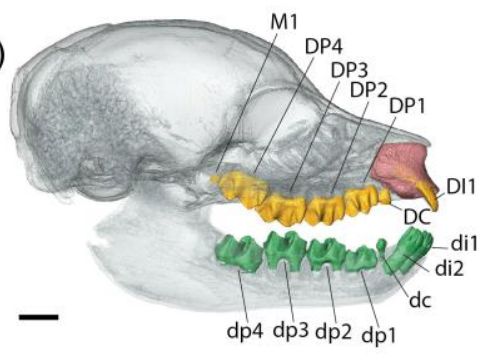

(o)

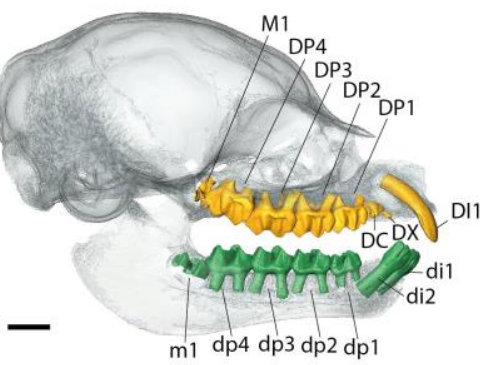


FIGURE 2 Reconstructions of the deciduous dentitions of extant hyraxes showing variation existing in the mesial part of the upper jaw. Procavia: MNHN 1901-685c, BMNH 48-244-266, MNHN 1961-44; Heterohyrax: USNM-1433-2, USNM-1433-1, USNM-181604; Dendrohyrax: MNHN 1883-868, RMCA-16049, RMCA-19881. The number of specimens observed for each phenotype is indicated in red. Mx stands for maxilla, and PMx for premaxilla.

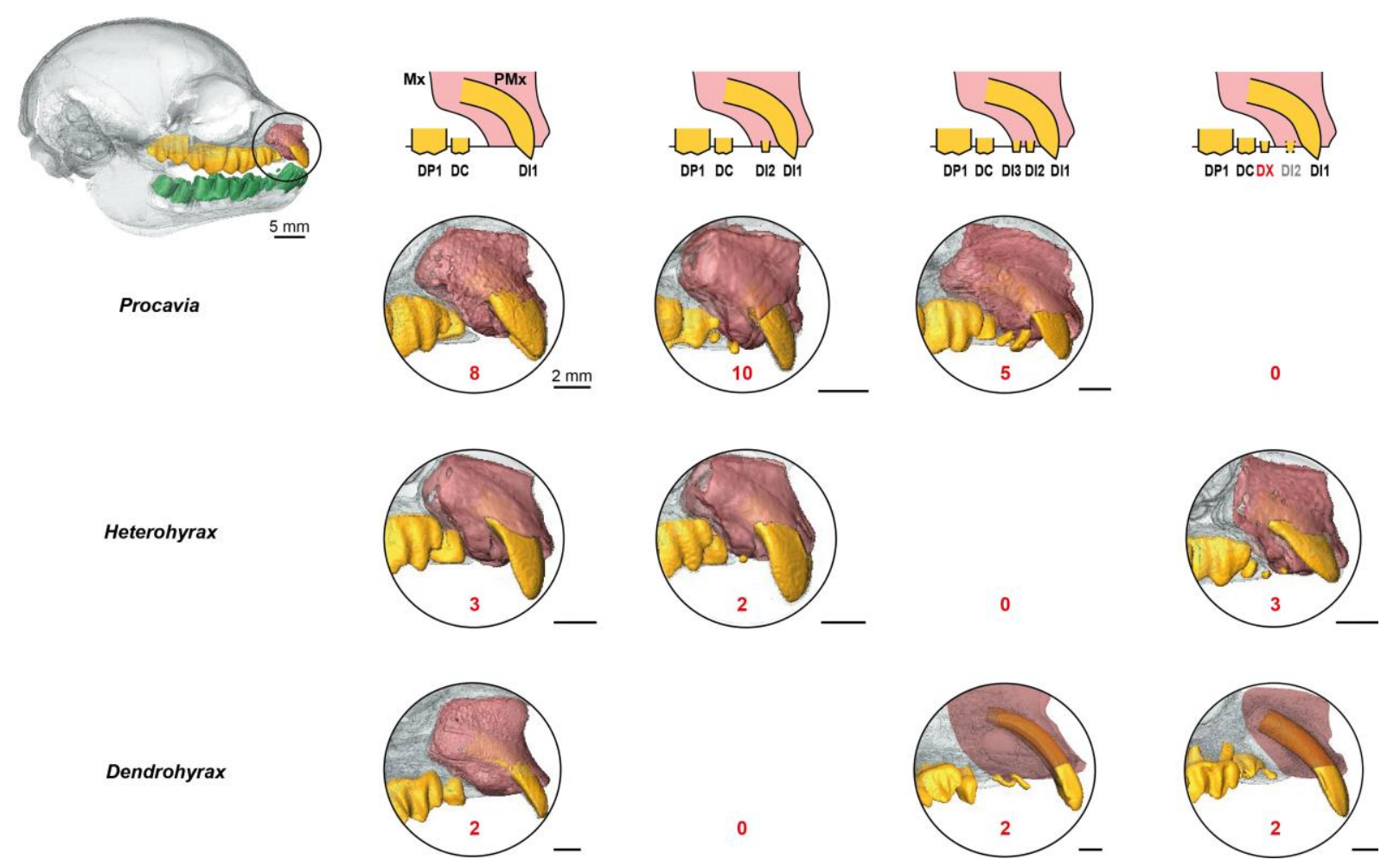


FIGURE 3 Rostra and crania in palatal view of a littermate of Procavia capensis. (a) CM51880, (b) CM51881, (c) CM51882, (d) CM51883. Arrows indicate vestigial teeth and the shaded line define the Pmx/Mx suture. Pictures courtesy of J. Wible.

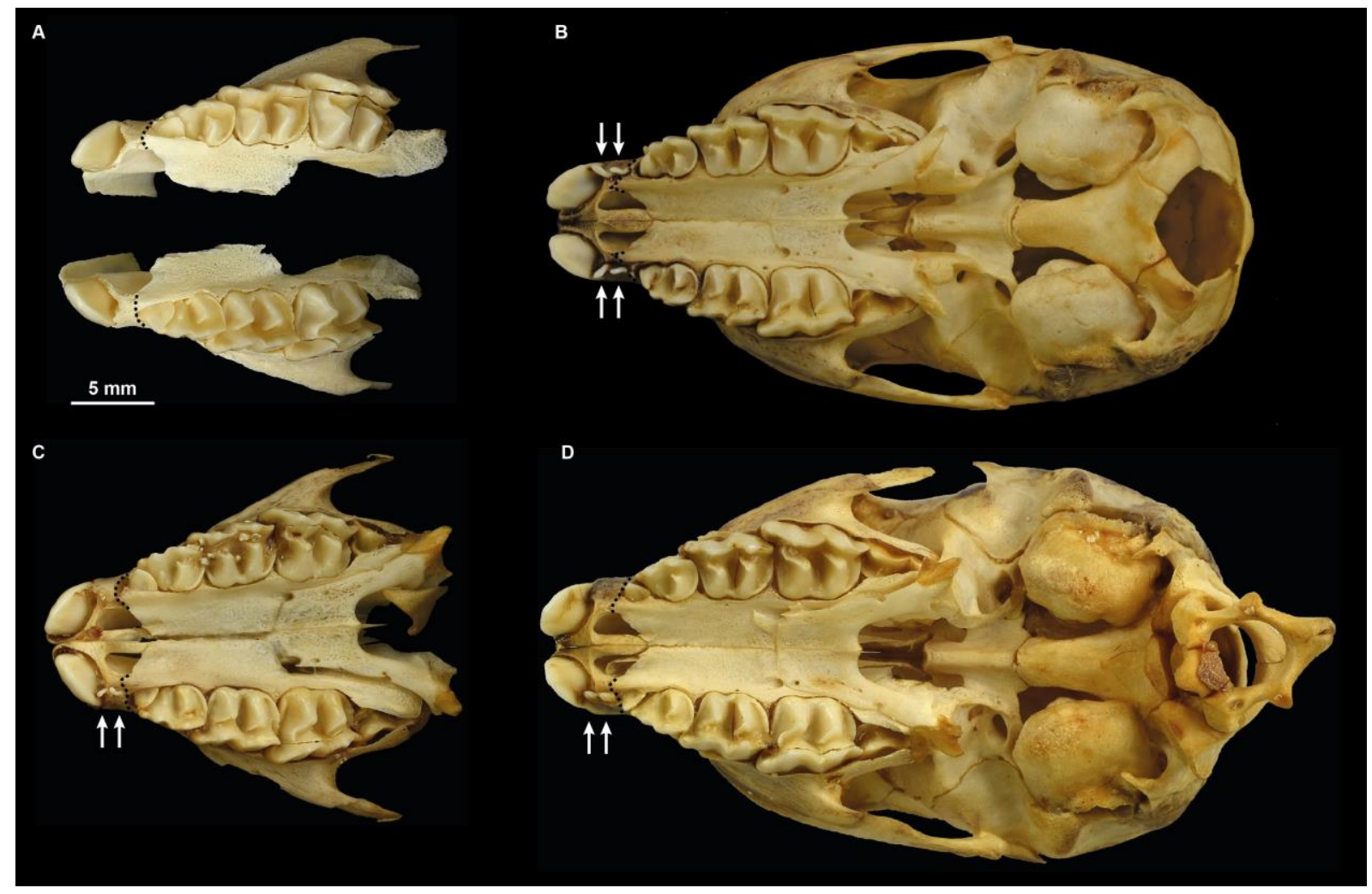


FIGURE 4 Mesial pattern of the upper deciduous dentition in extinct and extant hyracoids, comparing the morphology of deciduous canine (DC) with the first deciduous premolar (DP1). Simplified phylogeny and stratigraphic ranges are based on Barrow et al. (2010), Cooper et al. (2014), and Tabuce et al. (2017). Dendrohyrax dorsalis, (a) MNHN-CG-1977-257, (b) RMCA19776, (c) RMCA-19769; Parapliohyrax mirabilis, (d) MNHN.F.BML150; Bunohyrax fajumensis, (e) AMNH 14455; Microhyrax lavocati, (f) UM HGL50-181 (top specimen) and UM HGL10-19 (bottom specimen). The pink box represents the premaxilla, yellow boxes and circles represent tooth loci, and lines between them represent diastemata. Dashed lines in diagrams of dental row indicate when dental formula is estimated based on adult dentition. The rare occurrence of DI1 and DI2 in juvenile procaviids is indicated by X symbols in the premaxilla (DX are not mentioned). 


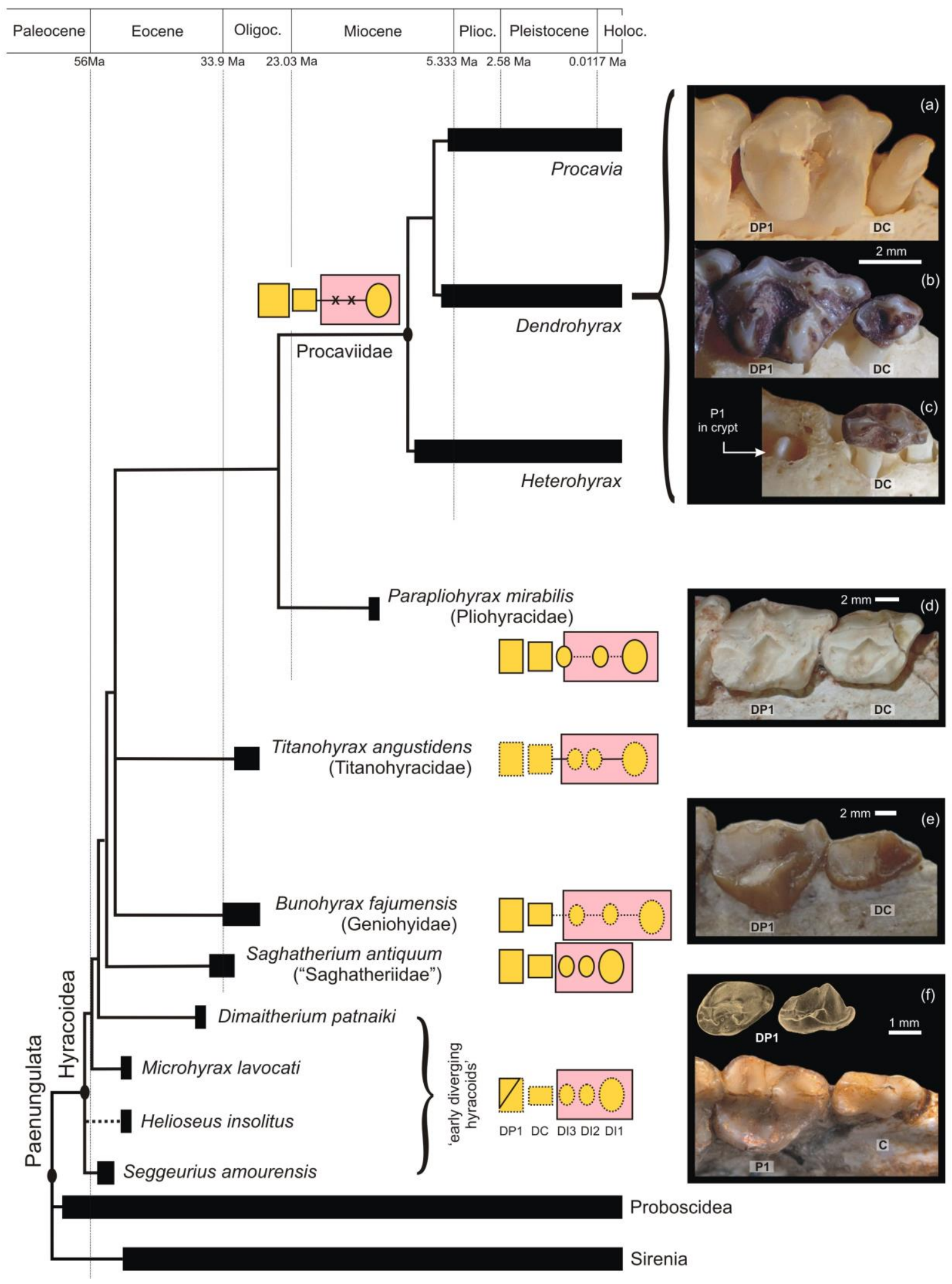


FIGURE 5 Reconstructions of two upper permanent dentitions of Helioseus insolitus. (a) UM HGL51-67 specimen showing the most common dental formula among extant placentals (3I, 1C, 4P, 3M). (b) UM HGL51-73 specimen (with the M3 broken) showing a supernumerary tooth on the maxilla in front of the canine, and could imply that the dental formula is $3 \mathrm{I}, 1 \mathrm{C}$, $5 \mathrm{P}, 3 \mathrm{M}$.

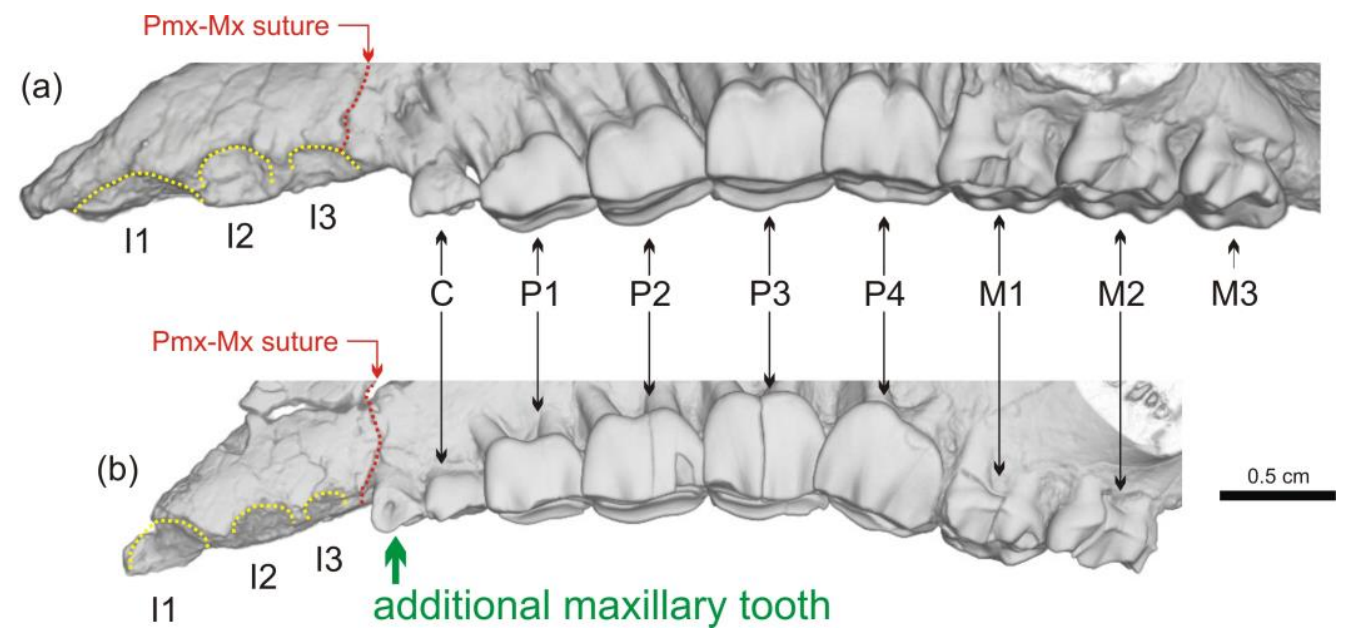


FIGURE 6 Putative developmental mechanisms involved in the mesial differentiation of the dentition in hyraxes (partly inspired from Luckett, 1993b, and Yamanaka et al., 2015). (a) Early stage of jaw development showing gene expression domains delineating incisors (in blue), and canine and premolars (in grey) in the mesenchyme. (b) Tooth initiation stage showing the mesial incisor (DI1) developing in the medial nasal prominence (MNP) and distal incisors (DI2, DI3) developing in the maxillary prominence (MxP). (c) Later stages of dental development showing the formation of the premaxilla (PMx) growing distally and of maxillary $(\mathrm{Mx})$ in the mesenchyme. (d) Normal location of the vestigial distal-most incisor on the premaxilla and resulting mineralization. (e) Distal migration of the vestigial distal-most incisor on the maxilla and resulting mineralization.

(a)

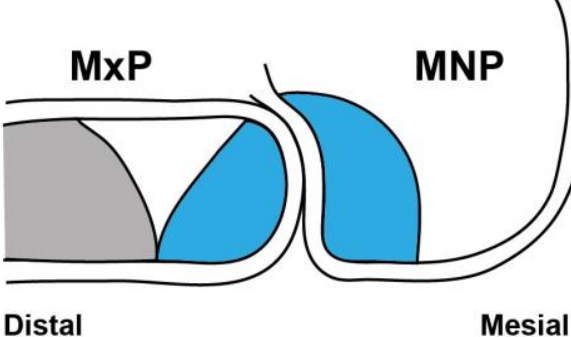

(c)

(d)
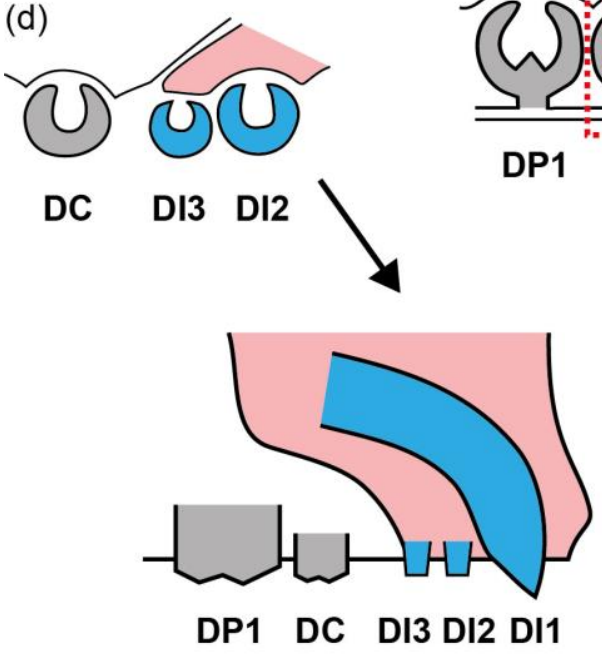

Normal development (b)

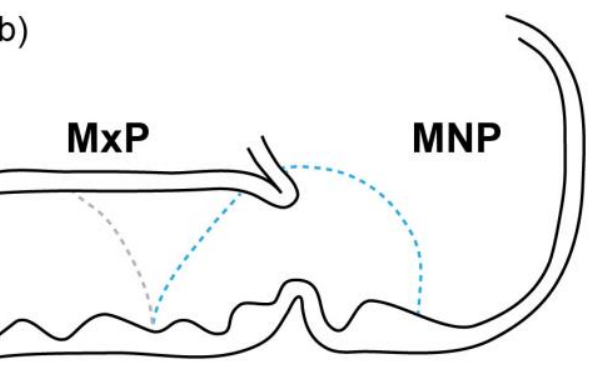

DP1 DC DI3 DI2 DI1

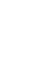

